\title{
FOOTPRINT ORTHOTICS USING 3D TECHNOLOGY
}

\author{
B. Susila, Henrich. P \\ Department of Mechanical Engineering \\ SNS Collège of Engineering, Coimbatore, India.
}

\begin{abstract}
Foot orthoses (FOs) are commonly used by people who having foot problems. This orthosis controls the motion of the ankle, compensate the weakness, and correct deformations at the foot. Foot orthoses can be helpful to support and position the weak limbs into a more normal position. So, we undertake to manufacture the customized orthotic foot insole using 3D technology, by using 3D scanning, 3D modelling and 3D printer. The structure of the customized foot insole was made by using Advanced 3D technology, 3D reworking of foot issues and then very specific to make the prescribed foot insole to control the abnormal movement of foot during gait. This customized foot orthotics manufactured by using 3D printers using Carbon fiber are expected to improve gait comfort and improve foot-loading characteristics, more efficiency than the normal orthotics and this method decrease the fabrication time and cost compared to conventional foot insole fabrication method. The correct design and fit of customized foot insole determine satisfied patient acceptance, comfort and restoration of normal foot function in terms of the weight and ease of use. These paper shows all the phases of model processing and manufacturing phases of a customized foot insole.
\end{abstract}

\section{Keywords-3D Printing, Orthotics, Patient care, Footwear.}

\section{INTRODUCTION}

Orthotics is a region of Healthcare that focuses on developing artificial devices to support a limb or the spine. So, we tend to gift a number of the foremost promising 3D printed orthotics, that aim to scale back the price, improve customization, and supply higher support. Orthotics is the devices worn by individuals to support their body. the foremost common sort of orthotics shoe insoles. they will be used to correct foot and ankle problems non-surgically. For additional serious or weakening conditions, ancient anklefoot orthotics will be wont to facilitate support and stabilize a personal. so as for these devices to be effective, they have to be bespoke and made for the actual person. additionally, to requiring fitting sessions, the device itself will take few hours to manufacture to urge delivered. 3D printing getting into the trade has allowed many teams to change fitting and customizing due to 3D Modelling and scanning. On the producing facet, $\quad 3 \mathrm{D}$ printing

\author{
Karthick Nadaraj. L.U, Kavinraj. K, Mohanaharish.M \\ Department of Mechanical Engineering \\ SNS Collège of Engineering, Coimbatore, India
}

has conjointly considerably reduced the quantity of your time needed to deliver orthotic devices to patients. The platform 3D planning and analysing the consumer's feet, measures foot pressure and analyses gait. With the ensuing knowledge, that is ready to form a fullycustomized innersole. The system prints the innersole victimisation Multi Jet Fusion (MJF) technology. The technique permits printing at the voxel level, providing a far better-quality innersole at 0.5 the price. Engineering answer This new platform can deliver customfitted and personal footwear through 3D modelling and analysing, dynamic gait analysis, and conjointly 3D printing. This creates a one-of-a-kind digital profile of every foot. The system can then 3D print innersole victimization HP's Multi Jet Fusion technology. This knowledge can alter people to own absolutely custom 3D written insoles created only for them. HP's 3D written technology offers superior quality physical components up to ten times quicker and 0.5 the price. Applications of RPT combined with completely different techniques for measure and modelling the figure are helpful to come up with new criteria for the orthotic device style. reckoning on the info acquisition methodology used, the info will be expressed as a degree cloud, voxels (3D meter pixels), or threedimensional coordinates of various anatomical points. Up to date, there's no standardized morphology acquisition procedure, however, there are many acquisition ways to support fabrication victimisation RPT at intervals the at intervals of orthotic devices modelling, as well as laptop imaging, 3D scanning, and completely different optical motion capture systems. the mixture of CAD and computed power-assisted producing (CAM) may be a well-known approach that's receiving increasing attention within the at intervals of orthotic devices to switch the standard craft practices. The custom producing through RPT requires: 3D Modelling and scanning of the anatomic surface, 3D surface reconstruction, CAD modelling, conversion to stereolithography format (STL) and, lastly, machining employing a special fast prototyping machine (i.e., a 3D printer) controlled through laptop. RPT provide blessings in producing processes of custom-fit orthotic devices, in terms of bigger style freedom, ability to form purposeful parts, superior accuracy and value efficiency, shorter delivery time, and higher user expertise of 
the expertise product. In AN RPT producing method, a representative virtual 3D CAD model is created layer upon layer to make an object. In RPT, a virtual model of the half is intended through CAD and is reborn to a STL file format, that is that the default commonplace file format for RP systems. AMT will be categorized in several ways that reckoning on the character of the fabrication method, like optical maser, printer technology, and extrusion technology. There are many various AM processes. Whereas producing by edge, grinding, and cutting removes material from a work, additive producing 3D-printing may be a digital technology that makes objects by selective material addition. Digital technologies \& 3D printed technology offers good quality physical parts up to 10 times faster and half the price.

\section{PROPOSED AlgORITHM}

\section{A. The Phases of Rapid Prototyping fabrication of Orthotics}

Customized fabrication through Rapid Prototyping requires these steps: Measurement of foot of the anatomic, 3D reconstruction of foot model, building of CAD model and converting to STL format and eventually machining employing a special Rapid Prototyping machine (3D printer) controlled through computer.

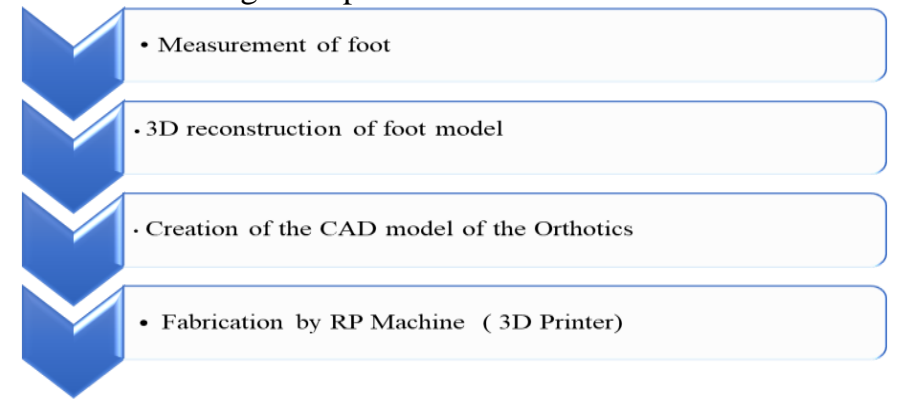

\section{B. Design of footprint orthotics -}

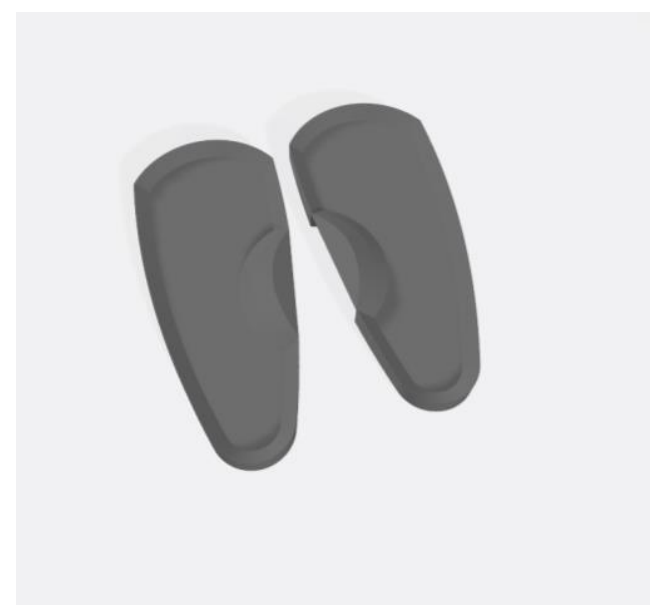

Fig. 1.Footprint OrthoticsDiagram
- $\quad$ Length-274 mm

- Width-82 mm

- Height-26.7 mm

\section{PROPERTIES OF PA11:}

\begin{tabular}{|l|l|}
\hline \multicolumn{1}{|c|}{ NAME } & \multicolumn{1}{c|}{ Nylon PA11 } \\
\hline Density & $1.03-1.05 \mathrm{~g} / \mathrm{cm} 3$ \\
\hline Young's modulus & $335 \mathrm{MPa}$ \\
\hline $\begin{array}{l}\text { Elongation } \\
\text { at break }\end{array}$ & $300-400 \%$ \\
\hline Melting point & $180-190^{\circ} \mathrm{C}$ \\
\hline
\end{tabular}

Table 1: Nylon of PA11

\section{METHODOLOGY}

- Manual Measurement of foot.

- 3D reconstruction of foot with standard size.

- Building CAD model and converting to STL format.

- Finally, system prints the insole using Multi Jet Fusion (MJF) technology (3D printer) controlled through computer.

\section{EXPERIMENT AND RESULT}

Walking in two conditions: wearing the standard shoes (Shoe) and wearing the shoes with 3D-printed Orthotics. BW: body weight

GRFs: ground reaction forces

Table -2 Experiment Result

\begin{tabular}{|c|c|c|c|c|}
\hline $\begin{array}{c}\text { Peak } \\
\text { GRF } \\
(B W)\end{array}$ & $\begin{array}{c}\text { Shoe } \\
(\text { mean } \pm \text { SD) }\end{array}$ & $\begin{array}{c}\text { Shoe+FO } \\
(\text { mean } \pm \text { SD })\end{array}$ & $\begin{array}{c}\mathrm{p} \\
\text { value }\end{array}$ & $\begin{array}{c}\text { Effect } \\
\text { size }\end{array}$ \\
\hline Anterior & $-0: 20 \pm 0: 05$ & $-0: 20 \pm 0: 04$ & 0.41 & 0.14 \\
\hline Posterior & $0: 17 \pm 0: 04$ & $0: 18 \pm 0: 04$ & 0.84 & 0.04 \\
\hline Medial & $-0: 06 \pm 0: 02$ & $-0: 07 \pm 0: 01$ & 0.39 & 0.21 \\
\hline Lateral & $0: 03 \pm 0: 02$ & $0: 03 \pm 0: 02$ & 0.57 & 0.12 \\
\hline Vertical & $1: 12 \pm 0: 06$ & $1: 12 \pm 0: 05$ & 0.66 & 0.06 \\
\hline
\end{tabular}

V. CONCLUSION

The 3D-printers within the fabrication of foot orthosis. projected solutions use the fore most economically laptop assisted instrumentation and software system during this domain. Also, solutions could facilitate the medical employees having poor engineering skills to fabricate orthosis or totally different items for orthosis and restorative. Most vital blessings of the employment of fast prototyping 3D technologies are: speed, repeatability, material uniformity and digital image capture. CAD software system, and 3D printers vary wide and have bit by bit return down over time. Our 3D-printed AFO targeted on the burden, individuation, and luxury instead 


\section{International Journal of Engineering Applied Sciences and Technology, 2020 \\ Vol. 4, Issue 12, ISSN No. 2455-2143, Pages 449-451 \\ Published Online April 2020 in IJEAST (http://www.ijeast.com)}

of the perform. It provides good level of customization for the user.

\section{REFERENCE}

[1] E. Suaste-Gomez, G. Rodriguez-Roldan, H. Reyes-Cruz, and O. Teran-Jimenez, "Developing an ear prosthesis fabricated in polyvinylidene fluoride by a 3D printer with sensory intrinsic properties of pressure and temperature," Sensors, vol. 16, no. 3 , 2016.

[2] J. Li, M. Chen, X. Fan, and H. Zhou, "Recent advances in bioprinting techniques: approaches, applications and future prospects," Journal of Translational Medicine, vol. 14, p. 271, 2016.

[3] E.K.Park,J.Y.Lim,I.S.Yunetal.,"Cranioplastyenhancedby three-dimensional printing: custom-made threedimensionalprinted titanium implants for skull defects," The Journal of Craniofacial Surgery, vol. 27, no. 4, pp. 943-949, 2016.

[4] S. Arabnejad, B. Johnston, M. Tanzer, and D. Pasini, "Fully porous 3D printed titanium femoral stem to reduce stressshielding following total hip arthroplasty," Journal of Orthopaedic Research, vol. 24, 2016.

[5] M. C. Wyatt, "Custom 3D-printed acetabular implants in hip surgery-innovative breakthrough or expensive bespoke upgrade?" Hip International, vol. 25, no. 4, pp. 375-379, 2015.

[6] J.Zuniga,D.Katsavelis,J.Pecketal., “Cyborgbeast:alow-cost 3d-printed prosthetic hand for children with upper-limb differences," BMC Research Notes, vol. 8, no. 10, p. 10, 2015.

[7] K. H. Lee, S. J. Kim, Y. H. Cha, J. L. Kim, D. K. Kim, and S. J. Kim, "Three-dimensional printed prosthesis demonstrates functional improvement in a patient with an amputated thumb: a technical note," Prosthetics and Orthotics International, 2016.

[8] R. Kaye, T. Goldstein, D. Zeltsman, D. A. Grande, and L. P. Smith, "Three-dimensional printing: a review on the utility within medicine and otolaryngology," International Journal of Pediatric Otorhinolaryngology, vol. 89, pp. 145-148, 2016.

[9] J.H.Pallari, K.W.Dalgarno, and J.Wood burn, "Mass customization of foot orthoses for rheumatoid arthritis using selective laser sintering," IEEE Transactions on bio-Medical Engineering, vol. 57, no. 7, pp. 1750-1756, 2010.

[10] A. S. Salles and D. E. Gyi, "The specification of personalized insoles using additive manufacturing," Work, vol. 41, Supplement 1, pp. 1771-1774, 2012.
[11] A. S. Salles and D. E. Gyi, "An evaluation of personalized insoles developed using additive manufacturing," Journal of Sports Sciences, vol. 31, no. 4, pp. 442-450, 2013.

[12] C. E. Dombroski, M. E. Balsdon, and A. Froats, "The use of a low-cost 3D scanning and printing tool in the manufacture of custom-made foot orthoses: a preliminary study," BMC Research Notes, vol. 10, no. 7, p. 443, 2014.

[13] L. Demers, M. Monette, Y. Lapierre, D. L. Arnold, and C. Wolfson, "Reliability, validity, and applicability of the Quebec User Evaluation of Satisfaction with assistive Technology (QUEST 2.0) for adults with multiple sclerosis," Disability and Rehabilitation, vol. 24, no. 1-3, pp. 21-30, 2002. 